\section{Potentials of CCL21 and CBS as Therapeutic Approaches for Breast Cancer}

\author{
Jing Peng Danhua Zhang \\ Department of General Surgery, The Second Xiangya Hospital, Central South University, Changsha, PR China
}

\section{Keywords}

Invasive breast cancer - Intraductal breast cancer - Lobular hyperplasia $\cdot$ CC chemokine ligand 21 . Cystathionine beta-synthase - Migration · Proliferation

\begin{abstract}
Objective: The present research set out to ascertain the roles of CC chemokine ligand 21 (CCL21) and cystathionine betasynthase (CBS) in breast cancer (BC) cell biological behaviors and the relationship of CCL21 and CBS expression with the clinicopathological features of patients with BC. Methods: Immunohistochemistry of CCL21 or CBS was performed in 18 intraductal cancer tissues, 124 invasive BC tissues, 50 paraneoplastic tissues, 50 lobular hyperplasia tissues, and 30 normal breast tissues. For cell experiments, two human BC cell lines (MDA-MB-231 and MCF-7) and a human breast epithelial cell line (MCF-10A) were utilized to detect the expression of CCL21 and CBS. After loss- and gain-of-function assays for CCL21 or CBS, the expression of CBS and CCL21 was measured by quantitative real-time polymerase chain reaction and western blot. Additionally, BC cell proliferation was assessed by 3-(4,5-dimethylthiazol-2-yl)-2,5-diphenyltetrazolium bromide assay and 5-ethynyl-2'-deoxyuridine staining, and $B C$ cell migration was determined by scratch test and
\end{abstract}

Transwell assay. Results: In the clinical data, the positive rate of CCL21 or CBS was significantly higher in invasive BC tissues than in intraductal BC tissues, lobular hyperplasia tissues, paraneoplastic tissues, and normal breast tissues $(p<$ 0.05 or $p<0.01)$. CBS or CCL21 expression shared close association with the clinicopathological characteristics and the poor prognosis of BC patients. In cell experiments, overexpression of CCL21 or CBS enhanced the proliferative and migratory abilities of BC cells. Conclusion: CCL21 and CBS promoted $B C$ cell migration and proliferation. CCL21 or CBS expression was strongly related to the poor prognosis of $B C$ patients.

(c) 2022 S. Karger AG, Basel

\section{Introduction}

Breast cancer (BC) is one of the most familiar malignancies and also the primary explanation of death from cancer in females around the world $[1,2]$. Invasive ductal carcinoma is the most prevalently occurring form of invasive $\mathrm{BC}$, followed by invasive lobular carcinoma [3]. The fatality rate of $\mathrm{BC}$ patients in China has doubled over the past 30 years [4]. At present, there exist numerous effective strategies for BC management, such as targeted 
therapy, surgery, hormonal therapy, chemotherapy, and radiotherapy [5]. Despite considerable progress in diagnostic and therapeutic approaches in recent years, $\mathrm{BC}$ remains a significant health problem and currently represents a top priority for biomedical research [6]. As multistep and complicated processes, tumor metastasis and invasion culminate in the overwhelming majority of BCassociated fatalities $[7,8]$. Notwithstanding, the primary cause of the occurrence and development of BC is still enigmatic [9]. Therefore, it is urgent to dissect the molecular mechanisms behind $\mathrm{BC}$ tumorigenesis for the determination of novel therapeutic targets and prognostic biomarkers for BC.

As the first enzyme in the transsulfuration pathway, cystathionine beta-synthase (CBS) functions as a key mammalian enzyme participating in a wide range of physiologic progressions [10, 11]. Accumulating evidence has addressed that the abnormally expressed CBS may be responsible for cancer progression. For example, CBS to protect $\mathrm{BC}$ cells against oxidative insults exogenously induced by immune cells [12]. A prior study reported that colon cancer cells could selectively overexpress CBS, which formed hydrogen sulfide to manage cellular bioenergetics and to facilitate vasorelaxation and angiogenesis [13]. In colorectal and ovarian cancers, CBS elicits a crucial effect on the promotion of the bioenergetics, proliferation, and migration of cancer cells [14]. Thus, CBS may possess the function of either accelerating or restraining tumor growth, which is dependent on the type of cancer cells.

CC chemokine ligand 21 (CCL21), a small cytokine, confers effects by binding to CCR7, a cell surface chemokine receptor [15]. CCR7 interacts with its ligands, CCL19 or CCL21, to promote lymphocyte transport and homing to lymph nodes during inflammatory and immune responses $[16,17]$. CCR7 or CCL21 is expressed in several types of tumors, including BC [18], thyroid carcinomas [19], esophageal squamous cell carcinoma [20], tongue carcinoma [21], and colorectal cancer [22], and their expression is linked to lymph node metastasis (LNM) and poor prognosis.

Considering the crucial role of CBS and CCL21 in various cancers, we tended to explore the therapeutic potentials of CCL21 and CBS in BC. Herein, we evaluated CCL21 and CBS expression in invasive BC tissues, intraductal $\mathrm{BC}$ tissues, lobular hyperplasia tissues, paraneoplastic tissues, and normal breast tissues by conducting immunohistochemistry. Additionally, the impacts of CBS and CCL21 on the biological behaviors of BC cells were analyzed.

\section{Materials and Methods}

\section{Samples}

We obtained 124 invasive BC tissues, 18 intraductal BC tissues, 50 paraneoplastic tissues $(2 \mathrm{~cm}$ from the tumor; patients with invasive $B C$ aged $32 \sim 70$ years [46.5 \pm 9.4$]), 50$ lobular hyperplasia tissues (patient aged $28 \sim 60$ years [ $36.7 \pm 8.4$ ] who underwent operation), and 30 normal breast tissues (normal tissues adjacent to breast fibroadenoma following pathological examination) from the Second and Third Xiangya Hospital of Central South University between January 2000 and December 2002. All samples were histologically confirmed by two pathologists.

As per the pathological examination, there existed 18 normal breast tissues, 14 mild dysplasia tissues, 10 moderately dysplasia tissues, and 8 severe dysplasia tissues among the paraneoplastic tissues. Additionally, the lobular hyperplasia tissues consisted of 16 normal breast tissues, 19 mild dysplasia tissues, 10 moderately dysplasia tissues, and 5 severe dysplasia tissues. Tumors were restaged and classified based on the grading classification scheme proposed by the 7 th edition of tumor node metastasis (TNM) Classification of Malignant Tumors and the World Health Organization Tumor Classification System. Table 1 shows the collected clinicopathological data of patients with intraductal BC or invasive BC.

This study was implemented by conforming to the Declaration of Helsinki. The study protocol concerning humans was ratified by the Ethics Committee of the Second Xiangya Hospital of Central South University, and written informed consent was acquired from all subjects. All tissues were immersed in $4 \%$ formaldehyde for $24 \sim 48 \mathrm{~h}$ and then routinely embedded in paraffin.

\section{Immunohistochemistry}

The EnVision immunohistochemistry of CBS and CCL21 was conducted with the use of an EnVision ${ }^{\mathrm{TM}}$ detection kit (positive control) and rabbit anti-human polyclonal antibodies against CBS and CCL21 (Dako Laboratories, Carpentaria, CA, USA). Briefly, 4- $\mu \mathrm{m}$ sections were subjected to deparaffinization and 15 - $\mathrm{min}$ incubation with $3 \% \mathrm{H}_{2} \mathrm{O}_{2}$ in the dark. Heat-induced antigen retrieval (30 min) was performed with sodium citrate buffer $(\mathrm{pH} \mathrm{6.0)}$ encompassing $10 \mathrm{~mm}$ sodium citrate and $0.05 \%$ Tween 20 at $96^{\circ} \mathrm{C}$. Subsequently, the sections were immersed in phosphate-buffered saline (PBS) for $3 \times 5 \mathrm{~min}$ and probed with primary rabbit antihuman antibodies against CBS and CCL21 (1:100) for $2 \mathrm{~h}$. Following $30 \mathrm{~min}$ of exposure to several drops of Solution A (ChemMateTMEnVison+/horseradish peroxidase), the sections were stained with 3,3'-diaminobenzidine and counterstained using hematoxylin. Following dehydration, the sections were permeated with xylene and mounted with neutral balsam. Five hundred cells from ten random fields were examined and averaged. Cases with positive cells $\geq 25 \%$ were regarded as positive, while the others were considered negative.

\section{Cell Culture and Transfection}

Human BC cell lines MDA-MB-231 and MCF-7 and human breast epithelial cell line MCF-10A (the Cell Bank of Type Culture Collection of Chinese Academy of Sciences, Shanghai, China) were soaked in Dulbecco's modified Eagle medium (DMEM) encompassing $10 \%$ fetal bovine serum (FBS) $\left(37^{\circ} \mathrm{C}, 5 \% \mathrm{CO}_{2}\right)$. The MDA-MB-231 and MCF-7 cells were seeded onto six-well plates and transfected with small interfering RNA against CBS (si-CBS), 
Table 1. Comparison of CBS and CCL21 expression levels

\begin{tabular}{llll}
\hline Tissue type & Case No. & CBS positive, $n(\%)$ & CCL21 positive, $n(\%)$ \\
\hline Invasive BC & 124 & $64(51.6)$ & $67(54.0)$ \\
Intraductal BC & 18 & $6(33.3)$ & $5(27.8)^{*}$ \\
Peritumoral & 50 & $11(22.0)^{* *}$ & $12(24.0)$ \\
Lobular hyperplasia & 50 & $9(18.0)^{* *}$ & $10(20.0)$ \\
Normal & 30 & $0(0.0)^{* *}$ & $0(0.0)^{* *}$ \\
\hline
\end{tabular}

${ }^{*} p<0.05 ; * *<0.01$, compared to invasive BC tissues.
si-CCL21, CBS overexpression plasmid (CBS), CCL21 overexpression plasmid (CCL21), or their negative controls (NCs), including si-NC and pcDNA3.1 (GenePharma, Shanghai, China) by utilizing the Lipofectamine-iMAX. The transfection dose of siRNAs was $100 \mathrm{nM}$ and the dose of the overexpression plasmids was $2 \mu \mathrm{g}$. Untransfected cells were allocated into a control group.

\section{3-(4,5-Dimethylthiazol-2-yl)-2,5-Diphenyltetrazolium}

Bromide Assay

Cells were cultured in 96-well microtitration plates $\left(5 \times 10^{3}\right.$ cells/well). After that, cells in each well were reacted with $10 \mu \mathrm{L}$ of 3-(4,5-dimethylthiazol-2-yl)-2,5-diphenyltetrazolium bromide (MTT) solution $(5 \mathrm{mg} / \mathrm{mL})$ for $4 \mathrm{~h}$ at $37^{\circ} \mathrm{C}$. The reaction was terminated by addition of $100 \mu \mathrm{L}$ dimethyl sulfoxide for overnight incubation at $37^{\circ} \mathrm{C}$. The optical density at $590 \mathrm{~nm}$ was assessed using a microplate reader (Sectramax 190; Molecular Devices Corp., Sunnyvale, CA, USA).

\section{5-Ethynyl-2'-Deoxyuridine Staining}

After cell seeding, cells in each well $\left(5 \times 10^{3}\right.$ cells) were incubated with $50 \mu \mathrm{M}$ 5-ethynyl-2'-deoxyuridine (EdU) dye (100 $\mu \mathrm{L}$; Sigma-Aldrich, Merck KGaA, Darmstadt, Germany) for $4 \mathrm{~h}$ at $37^{\circ} \mathrm{C}$. Following $30 \mathrm{~min}$ of fixation in $4 \%$ formaldehyde, cells were neutralized using glycine and immersed in $100 \mu \mathrm{L}$ of $1 \times$ Apollo mixture (Ribbio, China) for $30 \mathrm{~min}$. Cells were permeated with $0.5 \%$ Triton X-100 for $10 \mathrm{~min}$, followed by nuclear staining with Hoechst 33342 solution. Then, the cells were observed under a fluorescence microscope (Olympus, Tokyo, Japan).

\section{Scratch Test}

Cells were seeded on six-well plates. When cell confluence reached $90 \%$, cells were scratched using a $200-\mu \mathrm{L}$ sterile pipette tip. The floating cells were washed off with PBS, and culture medium was replaced with serum-free medium. The blank space between cells was observed with a low-power phase contrast microscope (Olympus). Twenty-four hours after additional culture, the blank space was recorded. The migration rate $=($ scratch distance at $0 \mathrm{~h}$ post-cell scratch - scratch distance at $24 \mathrm{~h}$ post-cell scratch)/ scratch distance at $0 \mathrm{~h}$ post-cell scratch.

Transwell Assay

Cells $\left(5 \times 10^{4}\right)$ were suspended in serum-free DMEM and then transferred into a Transwell chamber. The $600-\mu \mathrm{L}$ culture medium with $10 \%$ FBS was pipetted into the basolateral chamber. Following 48 -h co-incubation $\left(37^{\circ} \mathrm{C}, 5 \% \mathrm{CO}_{2}\right)$, the invaded cells underwent fixing in $100 \%$ methyl alcohol, followed by $0.1 \%$ crystal violet staining, whereas the non-invaded cells on the upper compart-
Table 2. Primer sequence information

\begin{tabular}{ll}
\hline Name & Primer \\
\hline CBS & F: 5'-CACACCATCGAGATCCTCCG-3' \\
& R: 5'-ATCCTACCTGGCCGACTTCT-3' \\
\hline CCL21 & F: 5'-AAGGAAGATTCCCGCCAAGG-3' \\
& R: 5'-TGTACTGGGGAGCCGTATCA-3' \\
\hline GAPDH & F: 5'-AATGGGCAGCCGTTAGGAAA-3' \\
& R: 5'-GCGCCCAATACGACCAAATC-3' \\
\hline
\end{tabular}

$F$, forward primer; $R$, reverse primer.

ment of the membrane were removed using a cotton swab. Then, cell migration was analyzed through microscopic (Olympus) observation and photographing in five random areas with a magnification of $\times 100$.

\section{Quantitative Real-Time Polymerase Chain Reaction}

Total cellular RNA was extracted by utilizing TRIzol (Thermo Fisher Scientific, Waltham, MA, USA), and then cDNA template was synthesized using a Reverse Transcription System (Promega, Madison, WI, USA). Gene expression was assessed on a LightCycler 480 real-time PCR instrument (Roche, Indianapolis, IN, USA). The reaction conditions were concordant with the manuals of the fluorescent quantitative polymerase chain reaction (PCR) kit (SYBR Green Mix; Roche). The thermal cycle parameters were as follows: $95^{\circ} \mathrm{C}$ for $5 \mathrm{~min}$, followed by 40 cycles of $95^{\circ} \mathrm{C}$ for $10 \mathrm{~s}$, $60^{\circ} \mathrm{C}$ for $10 \mathrm{~s}$, and $72^{\circ} \mathrm{C}$ for $20 \mathrm{~s}$. Glyceraldehyde-3-phosphate dehydrogenase (GAPDH) was regarded as the loading control for PCR amplification, and the $2^{-\Delta \Delta C t}$ method was employed for data analysis. The primers are displayed in Table 2.

\section{Western Blot}

Cells were lysed with Radioimmunoprecipitation assay lysis buffer containing Halt protease inhibitors (Pierce, Rockford, IL, USA) and phosphatase inhibitors (Cayman Chemical, Ann Arbor, MI, USA), followed by protein concentration measurement with the Bradford method. Then, proteins were subjected to sodium dodecyl sulfate polyacrylamide gel electrophoresis at $120 \mathrm{~V}$, followed by transferring into polyvinylidene fluoride membranes. Following 1-h sealing in Tris-buffered saline Tween (TBST) encompassing $0.05 \mathrm{~g} / \mathrm{mL}$ bovine serum albumin, the membranes were probed with the primary rabbit antibodies against GAPDH 


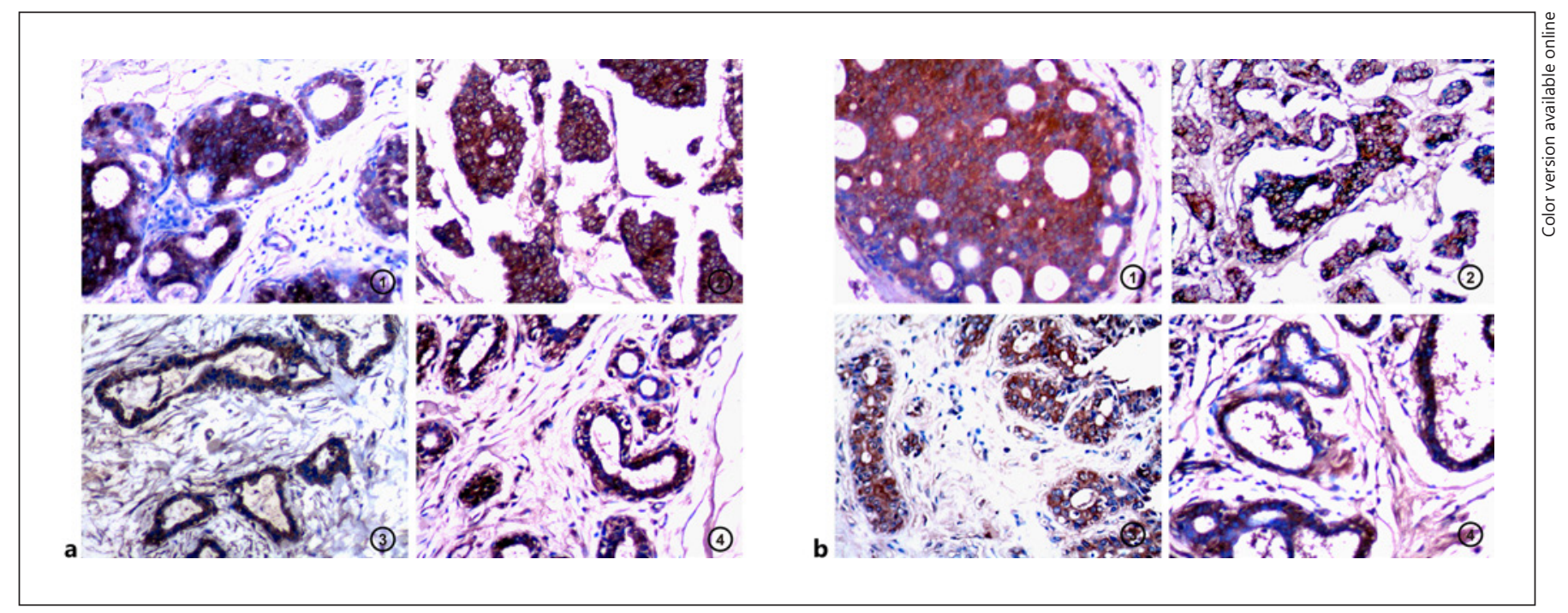

Fig. 1. Expression of CBS and CCL21 in BC tissues. Expression of CBS (a) and CCL21 (b) was detected using immunohistochemistry. a1 Positive expression of CBS in intraductal BC tissues, $\times 200$. a2 Psitive expression of CBS in invasive BC tissues, $\times 200$. a3 Positive expression of CBS in paraneoplastic tissues, $\times 200$. a4 Positive expression of CBS in lobular hyperplasia tissues, $\times 200$. b1 Positive expression of CCL21 in intraductal BC tissues, $\times 200$. b2 Positive expression of CCL 21 in invasive BC tissues, $\times 200$. b3 Positive expression of CCL21 in paraneoplastic tissues, $\times 200$. b4 Positive expression of CCL2 1 in lobular hyperplasia tissues, $\times 200$. BC, breast cancer. The same negative control for CBS and CCL21 are shown in the online supplementary material (for all online suppl. material, see www.karger.com/doi/10.1159/000521671).

(1:10,000, ab181602), CBS (1:500, ab140600), and CCL21 (1:1,000, ab129014) overnight at $4^{\circ} \mathrm{C}$. Following TBST wash, the membranes underwent 2 -h re-probing with the goat anti-rabbit immunoglobulin G (1:5,000; ComWin, Beijing, China) at room temperature. Pictures were captured using a chemiluminescence imaging system (GE Healthcare, Beijing, China) after the membranes were washed thrice with TBST.

\section{Statistical Analysis}

The data were processed using SPSS 17.0. Data were summarized as mean \pm standard deviation. The $T$ test was employed for comparisons between two groups. Comparisons among multiple groups were analyzed with one-way analysis of variance. The interrelationship of CBS and CCL21 with histological or clinical factors was analyzed by using $\chi^{2}$ test or Fisher's exact test. The overall survival of patients with $\mathrm{BC}$ was assessed using log-rank tests and Kaplan-Meier univariate survival analysis. Multivariate analysis was performed with a Cox proportional hazards model, followed by the calculation of $95 \%$ confidence interval (CI). $p$ values of significance were those at $p<0.05$.

\section{Results}

\section{Expressions of CCL21 and CBS}

The results of immunohistochemistry presented that the positive expression of CBS and CCL21 was located in the cytoplasm (Fig. 1a-b). Subsequently, the expression of CCL2 1 and CBS was analyzed in different tissues (Table 1). In the 124 cases of invasive $\mathrm{BC}$ tissues, the positive rate of CBS or CCL21 was $51.6 \%$ or $54.0 \%$, respectively. Among the 18 intraductal BC tissues, 6 cases were positive for CBS (33.3\%) and 5 cases for CCL21 $(27.8 \%)$. There was $22 \%$ or $24 \%$ positive rate of CBS or CCL21 in the 50 cases of paraneoplastic tissues. In the lobular hyperplasia tissues, CBS expression was found in 9 of 50 cases (18\%) and CCL21 expression was observed in 10 of 50 cases (20\%). Furthermore, there was no expression of CBS and CCL21 in 30 normal tissues. The positive rates of CCL21 and CBS in invasive BC tissues were notably higher than those in paraneoplastic tissues, lobular hyperplasia tissues, and normal tissues (Table $1, p<0.05$ or $p<$ 0.01 ). The positive rate of CBS or CCL21 was increased in invasive $\mathrm{BC}$ tissues in contrast to intraductal $\mathrm{BC}$ tissues (Table $1, p<0.05$ ). Additionally, the lobular hyperplasia tissues and paraneoplastic tissues with positive expression of CBS and/or CCL21 exhibited moderate to severe dysplasia (Table 1).
Peng/Zhang 
Table 3. Comparison of the clinicopathological features and the expression of CBS and CCL21 in intraductal or invasive BC

\begin{tabular}{|c|c|c|c|c|c|}
\hline \multirow[t]{2}{*}{ CPC } & \multirow[t]{2}{*}{$n$} & \multirow{2}{*}{$\frac{\text { Intraductal BC }}{\text { positive, } n(\%)}$} & \multicolumn{2}{|l|}{ Invasive BC } & \multirow[t]{2}{*}{$p$ value } \\
\hline & & & positive, $n(\%)$ & $x^{2}$ & \\
\hline \multicolumn{6}{|l|}{ Age, years } \\
\hline$\leq 45$ & 81 & $13(72.2)$ & $68(54.8)$ & \multirow{2}{*}{1.938} & \multirow{2}{*}{0.164} \\
\hline$>45$ & 61 & $5(27.8)$ & $56(45.2)$ & & \\
\hline \multicolumn{6}{|l|}{ Menopausal status } \\
\hline Premenopausal & 80 & $9(50.0)$ & $71(57.3)$ & \multirow{2}{*}{0.337} & \multirow{2}{*}{0.562} \\
\hline Postmenopausal & 62 & $9(50.0)$ & $53(42.7)$ & & \\
\hline \multicolumn{6}{|l|}{ Histologic grade } \\
\hline I & 22 & $5(27.8)$ & $17(13.7)$ & \multirow{3}{*}{11.132} & \multirow{3}{*}{0.004} \\
\hline II & 61 & $12(66.7)$ & 49 (39.5) & & \\
\hline III & 59 & $1(5.6)$ & $58(46.8)$ & & \\
\hline \multicolumn{6}{|l|}{ Tumor size, $\mathrm{cm}$} \\
\hline$\leq 3$ & 72 & $15(83.3)$ & $57(46.0)$ & \multirow{2}{*}{8.870} & \multirow{2}{*}{0.003} \\
\hline$>3$ & 70 & $3(16.7)$ & $67(54.0)$ & & \\
\hline \multicolumn{6}{|l|}{ ER } \\
\hline+ & 73 & $14(77.8)$ & $59(47.6)$ & \multirow{2}{*}{5.738} & \multirow{2}{*}{0.017} \\
\hline- & 69 & $4(22.2)$ & $65(52.4)$ & & \\
\hline \multicolumn{6}{|l|}{ PR } \\
\hline+ & 79 & $15(83.3)$ & $64(51.6)$ & \multirow{2}{*}{6.408} & \multirow{2}{*}{0.011} \\
\hline- & 63 & $3(16.7)$ & $60(48.4)$ & & \\
\hline \multicolumn{6}{|l|}{ CerB2 } \\
\hline+ & 85 & 7 (38.9) & $78(62.9)$ & \multirow{2}{*}{3.773} & \multirow{2}{*}{0.052} \\
\hline- & 57 & $11(61.1)$ & $46(37.1)$ & & \\
\hline \multicolumn{6}{|l|}{ LNM } \\
\hline No & 73 & $17(94.4)$ & $56(45.2)$ & \multirow[b]{2}{*}{15.283} & \\
\hline Yes & 69 & $1(5.6)$ & $68(54.8)$ & & 0.000 \\
\hline TNM stage & & & & & \\
\hline$I+I I$ & 83 & $17(94.4)$ & $66(53.2)$ & & \\
\hline III + IV & 59 & $1(5.6)$ & $58(46.8)$ & 10.081 & 0.014 \\
\hline CCL21 & & & & & \\
\hline+ & & $5(27.8)$ & $67(54.0)$ & & \\
\hline- & & $13(72.2)$ & $57(46.0)$ & 4.335 & 0.037 \\
\hline CBS & & & & & \\
\hline+ & & $6(33.3)$ & 64 (51.6) & & \\
\hline- & & $12(66.7)$ & $60(48.4)$ & 2.101 & 0.147 \\
\hline
\end{tabular}

$\mathrm{BC}$, breast cancer; $\mathrm{CPC}$, clinicopathological characteristics; ER, estrogen receptor; PR, progesterone receptor; LNM, lymph node metastasis; TNM, tumor node metastasis; -, negative expression; +, positive expression.

Interrelationship of CBS or CCL21 Expression with Overall Survival and Clinicopathological Features of Patients with Invasive BC

Given the high positive rates of CBS and CCL21 in invasive $B C$ tissues, the investigation was performed on the associations of the expression of CBS and CCL21 with the clinicopathological features of $\mathrm{BC}$ patients. As depicted in Table 3, the percentages in invasive $\mathrm{BC}$ tissues regarding histologic grade III, tumor size $>3 \mathrm{~cm}$, estrogen receptor $(-)$, progesterone receptor $(-)$, LNM, and TNM stage III
+ IV were signally augmented versus intraductal BC tissues $(p<0.05$ or $p<0.01)$. Additionally, CCL21-positive rate was elevated in invasive $\mathrm{BC}$ tissues rather than in intraductal BC tissues $(p<0.05)$.

As displayed in Table 4, the positive rates of CBS and CCL21 were obviously lower in cases with no LNM, TNM stage I + II, and histologic grade I in comparison to cases with LNM, TNM stage III + IV, and histologic grade III $(p<0.05$ or $p<0.01)$. The expression of CBS and CCL2 1 exhibited no conspicuous association with patient age, 
Table 4. Correlations of CBS and CCL21 expression with the clinicopathological features of patients with invasive $\mathrm{BC}$

\begin{tabular}{|c|c|c|c|c|c|c|c|}
\hline \multirow[t]{2}{*}{ CPC } & \multirow[t]{2}{*}{$n$} & \multicolumn{3}{|l|}{ CBS } & \multicolumn{3}{|l|}{ CCL21 } \\
\hline & & positive, $n(\%)$ & $x^{2}$ & $p$ value & positive, $n(\%)$ & $x^{2}$ & $p$ value \\
\hline \multicolumn{8}{|l|}{ Age, years } \\
\hline$\leq 45$ & 68 & $37(54.5)$ & \multirow{2}{*}{0.472} & \multirow{2}{*}{0.492} & $39(57.4)$ & \multirow{2}{*}{0.668} & \multirow{2}{*}{0.414} \\
\hline$>45$ & 56 & $27(48.2)$ & & & $28(50.0)$ & & \\
\hline \multicolumn{8}{|l|}{ Menopausal status } \\
\hline Premenopausal & 71 & $40(56.3)$ & \multirow{2}{*}{1.485} & \multirow{2}{*}{0.223} & $44(62.0)$ & \multirow{2}{*}{4.216} & \multirow{2}{*}{0.040} \\
\hline Postmenopausal & 53 & $24(45.3)$ & & & $23(43.3)$ & & \\
\hline \multicolumn{8}{|l|}{ Histologic grade } \\
\hline I & 17 & $4(23.5)$ & \multirow{3}{*}{29.689} & \multirow{3}{*}{0.000} & $4(23.5)$ & \multirow{3}{*}{19.254} & \multirow{3}{*}{0.000} \\
\hline II & 49 & $15(30.6)$ & & & $20(40.8)$ & & \\
\hline III & 58 & $45(77.6)$ & & & $43(74.5)$ & & \\
\hline \multicolumn{8}{|l|}{ Tumor size, $\mathrm{cm}$} \\
\hline$\leq 3$ & 57 & $25(43.9)$ & \multirow{2}{*}{2.539} & \multirow{2}{*}{0.111} & $27(47.4)$ & \multirow{2}{*}{1.886} & \multirow{2}{*}{0.170} \\
\hline$>3$ & 67 & $39(58.2)$ & & & $40(59.7)$ & & \\
\hline \multicolumn{8}{|l|}{ ER } \\
\hline+ & 59 & $26(44.1)$ & \multirow{2}{*}{2.566} & \multirow{2}{*}{0.109} & $29(49.2)$ & \multirow{2}{*}{1.079} & \multirow{2}{*}{0.299} \\
\hline- & 65 & $38(58.5)$ & & & $38(58.5)$ & & \\
\hline \multicolumn{8}{|l|}{ PR } \\
\hline+ & 64 & $33(51.6)$ & & & $34(53.1)$ & & \\
\hline- & 60 & $31(51.6)$ & 0.000 & 0.991 & $33(55.0)$ & 0.044 & 0.834 \\
\hline CerB2 & & & & & & & \\
\hline+ & 78 & $44(56.4)$ & & & $44(56.4)$ & & \\
\hline- & 46 & $20(43.5)$ & 1.938 & 0.164 & $23(50.0)$ & 0.479 & 0.489 \\
\hline LNM & & & & & & & \\
\hline No & 56 & $18(32.1)$ & & & $24(42.9)$ & & \\
\hline Yes & 68 & $46(67.6)$ & 15.501 & 0.000 & $43(63.2)$ & 5.135 & 0.023 \\
\hline TNM stage & & & & & & & \\
\hline$I+I I$ & 66 & $19(28.8)$ & & & 25 (37.9) & & \\
\hline III + IV & 58 & 45 (77.6) & 29.435 & 0.000 & $42(72.4)$ & 14.824 & 0.000 \\
\hline
\end{tabular}

$\mathrm{BC}$, breast cancer; CPC, clinicopathological characteristics; ER, estrogen receptor; PR, progesterone receptor; LNM, lymph node metastasis; TNM, tumor node metastasis; -, negative expression; +, positive expression.

tumor size, estrogen receptor, progesterone receptor, and CerbB2 statuses $(p>0.05)$. Among the 64 cases with positive CBS expression, 44 cases had positive CCL21 expression. Among the 60 cases with reduced CBS expression, 37 cases had decreased CCL21 expression. CBS expression was positively correlated with CCL21 expression $\left(\chi^{2}\right.$ $=11.535, p=0.001$ ).

Survival information of patients with invasive BC was harvested through letters and/or telephone calls within 13 years. Of the 124 patients with invasive BC, 98 patients died within 13 years, while 26 patients survived longer than 13 years, which were enrolled in the analysis as censored cases. Kaplan-Meier survival analysis demonstrated that tumor size $>3 \mathrm{~cm}$, the histologic grade III, LNM, and advanced TNM stages strikingly correlated to the overall survival time of patients with invasive BC (Table $5, p<0.05$ or $p<0.01)$. The overall survival time of CBS- or CCL21-positive patients was substantially shorter than that of CBS- or CCL21-negative patients (Fig. 2ab, Table 5, $p=0.000$ ). Multivariate Cox regression analysis manifested that histologic grade III, tumor size $>3 \mathrm{~cm}$, LNM, and high TNM stages had positive correlation with the fatality rate and negative correlation with the overall survival. CBS or CCL21 expression was inversely associated with the overall survival and positively correlated to the fatality rate. Both CBS expression and CCL21 expression were independent prognostic factors (Table 6). The area under the curve for CCL21 was 0.670 (95\% CI: $0.578-$ 0.762 ) and that for CBS was 0.658 (95\% CI: 0.565-0.751) (Fig. 2c-d). 
Table 5. Correlations among clinicopathological features, CBS and CCL21 expression, and the overall survival rate in patients with invasive $\mathrm{BC}$

\begin{tabular}{|c|c|c|c|c|}
\hline Group & Cases, $n$ & Mean survival (years) & $x^{2}$ & $p$ value \\
\hline \multicolumn{5}{|l|}{ Age, years } \\
\hline$\leq 45$ & 68 & $8.22(0.2-13.0)$ & \multirow{2}{*}{0.134} & \multirow{2}{*}{0.714} \\
\hline$>45$ & 56 & $8.99(0.8-13.0)$ & & \\
\hline \multicolumn{5}{|l|}{ Menopausal status } \\
\hline Premenopausal & 71 & $7.97(0.2-13.0)$ & \multirow{2}{*}{2.261} & \multirow{2}{*}{0.133} \\
\hline Postmenopausal & 53 & $9.33(0.8-13.0)$ & & \\
\hline \multicolumn{5}{|l|}{ Pathologic type } \\
\hline \multicolumn{5}{|l|}{ ER } \\
\hline+ & 59 & $9.75(0.7-13.0)$ & \multirow{2}{*}{1.847} & \multirow{2}{*}{0.174} \\
\hline- & 65 & $7.48(0.2-13.0)$ & & \\
\hline \multicolumn{5}{|l|}{ PR } \\
\hline+ & 64 & $9.02(0.7-13.0)$ & \multirow{2}{*}{0.019} & \multirow{2}{*}{0.891} \\
\hline- & 60 & $8.05(0.2-13.0)$ & & \\
\hline \multicolumn{5}{|l|}{ CerbB2 } \\
\hline+ & 78 & $8.17(0.7-13.0)$ & \multirow{2}{*}{0.688} & \multirow{2}{*}{0.407} \\
\hline- & 46 & $9.17(0.2-13.0)$ & & \\
\hline \multicolumn{5}{|l|}{ Histologic grade } \\
\hline I & 17 & $13.51(11.2-13.0)$ & \multirow{3}{*}{61.642} & \multirow{3}{*}{0.000} \\
\hline II & 49 & $11.36(3.0-13.0)$ & & \\
\hline III & 58 & $4.70(0.2-13.0)$ & & \\
\hline \multicolumn{5}{|l|}{ Tumor size, $\mathrm{cm}$} \\
\hline$\leq 3$ & 57 & $10.11(1.0-13.0)$ & \multirow[b]{2}{*}{8.604} & \multirow{2}{*}{0.003} \\
\hline$>3$ & 67 & $7.19(0.2-13.0)$ & & \\
\hline \multicolumn{5}{|l|}{ TNM stage } \\
\hline$I+I I$ & 35 & $18.57(7-30)$ & \multirow{2}{*}{57.569} & \multirow{2}{*}{0.000} \\
\hline III + IV & 38 & $11.05(3-30)$ & & \\
\hline \multicolumn{5}{|l|}{ LNM } \\
\hline No & 56 & $10.73(0.8-13.0)$ & \multirow{2}{*}{9.214} & \\
\hline Yes & 68 & $6.77(0.2-13.0)$ & & 0.002 \\
\hline Invasion & & & & \\
\hline No & 33 & $17.52(4-30)$ & & \\
\hline Yes & 67 & $9.87(3-30)$ & 17.399 & 0.000 \\
\hline CBS & & & & \\
\hline- & 60 & $12.38(3.0-13.0)$ & & 0000 \\
\hline+ & 64 & $5.02(0.2-13.0)$ & 53.153 & 0.000 \\
\hline CCL21 & & & & \\
\hline- & 57 & $12.03(3.3-13.0)$ & 19877 & ( \\
\hline+ & 67 & $5.57(0.2-13.0)$ & 49.817 & 0.000 \\
\hline
\end{tabular}

$\mathrm{BC}$, breast cancer; ER, estrogen receptor; PR, progesterone receptor; LNM, lymph node metastasis; TNM, tumor node metastasis; - , negative expression; +, positive expression.
Upregulation of CBS or CCL21 Contributes to Enhanced BC Cell Proliferative and Migratory Properties

To further dissect the influence of CBS or CCL21 on BC, the expression patterns of CCL21 and CBS were measured in human BC cell lines (MDA-MB-231 and MCF-7) as well as in a human normal breast epithelial cell line MCF-10A. The results of quantitative real-time (qRT) PCR and western blot illustrated higher expression of CCL21 and CBS in MDA-MB-231 and MCF-7 cells than in MCF-10A cells
(Fig. 3a-b, $p<0.05$ or $p<0.01$ ), indicating the consistencies of CCL21 and CBS expression in BC cells and tissues. Then, CBS or CCL21 was overexpressed in MDA-MB-231 and MCF-7 cells, and the transfection efficiencies of CBS overexpression plasmid and CCL21 overexpression plasmid were assessed with qRT-PCR and western blot. The overexpression plasmid of CBS or CCL21 substantially potentiated the expression of CBS or CCL21 (Fig. $3 c-d, p<0.001$ or $p<0.01$ ), indicating the successful transfection of the overexpression plasmids of CBS and CCL21. 
Table 6. Multivariate Cox regression analysis of the correlation between the survival rate for patients with invasive $\mathrm{BC}$ and the expression of CBS and CCL21

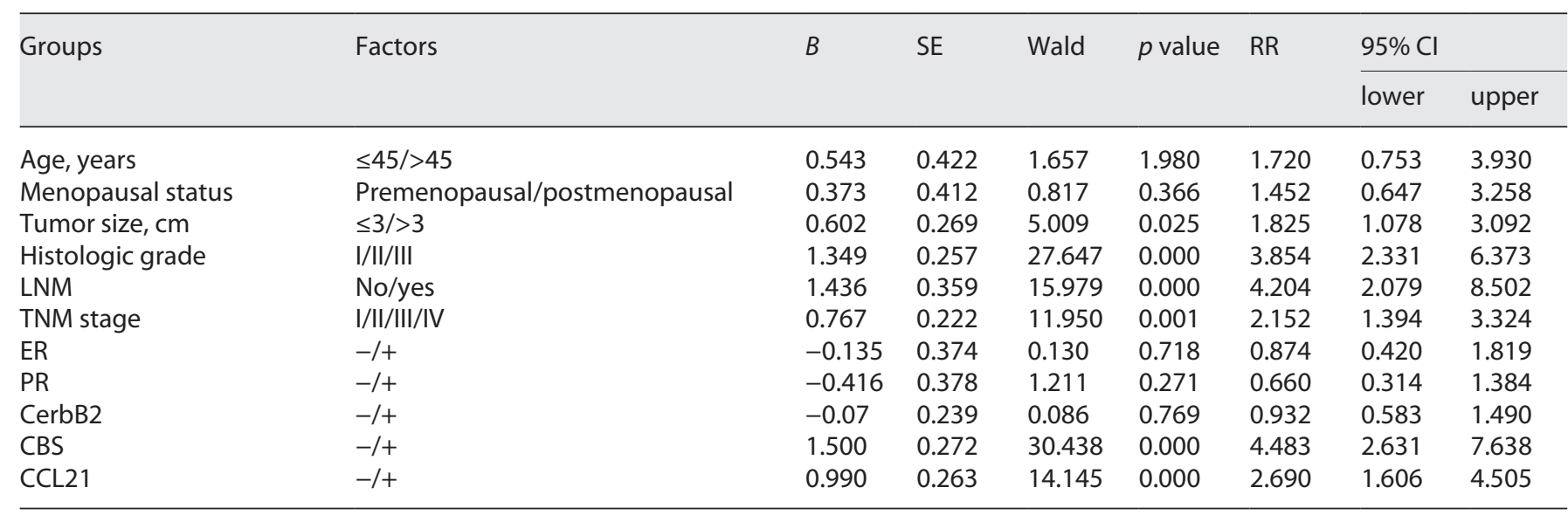

$\mathrm{SE}$, standard error; RR, relative risk; Cl, confidence interval; LNM, lymph node metastasis; TNM, tumor node metastasis; ER, estrogen receptor; PR, progesterone receptor; -, negative expression; +, positive expression.

The results of MTT and EdU staining displayed that the transfection with plasmid overexpressing CBS or CCL21 strikingly enhanced BC cell proliferation (Fig. 3e$\mathrm{f}, p<0.05$ or $p<0.01$ ). Additionally, scratch test and Transwell assay exhibited that upregulation of CCL21 or CBS augmented the migratory property of BC cells (Fig. 3g-h, $p<0.05$ or $p<0.01$ ). Taken together, overexpression of CBS or CCL21 might reinforce the migratory and proliferative potentials of $\mathrm{BC}$ cells.

Suppression of CCL21 or CBS Inhibits the Proliferative and Migratory Properties of BC Cells

Subsequently, CBS and/or CCL21 were silenced in MDA-MB-231 and MCF-7 cells using si-CBS and/or siCCL2 1 to verify the role of CCL21 or CBS in BC cells. The transfection with si-CBS diminished CBS expression $(p<$ 0.001 or $p<0.05$ ) and did not alter CCL21 expression in MDA-MB-231 and MCF-7 cells, while the transfection with si-CCL21 triggered the reduction of CCL21 expression $(p<0.001$ or $p<0.05)$ and did not change CBS expression in MDA-MB-231 and MCF-7 cells (Fig. 4a-d).

The results of MTT assay, EdU staining, scratch test, and Transwell assay documented that silencing of CBS or CCL21 effectively reduced the proliferative and migratory properties of MDA-MB-231 and MCF-7 cells $(p<$ $0.05)$. Furthermore, the co-transfection of si-CBS and siCCL21 further suppressed the proliferative and migratory capabilities of BC cells (Fig. $4 \mathrm{e}-\mathrm{h}, p<0.01$ ).

\section{Discussion}

The current research analyzed the expression of CBS and CCL21 in intraductal BC tissues, invasive BC tissues, paraneoplastic tissues, lobular hyperplasia tissues, and normal breast tissues with immunohistochemistry. The results indicated a marked increase in the expression of CCL21 and CBS in invasive BC tissues. The expression of CBS and CCL21 was associated with high histological grades, advanced TNM stages, poor prognosis, and LNM of patients with invasive BC. Additionally, CBS or CCL21 was responsible for the enhanced proliferative and migratory properties of $\mathrm{BC}$ cells.

CBS is a metabolic enzyme that catalyzes the reaction of homocysteine with either serine or cysteine to produce cystathionine, water, or hydrogen sulfide, respectively [23]. A former study elucidated that CBS could serve as a potential target in relapsed and platinum-resistant ovarian cancer [24]. Furthermore, the catalytic activities and the protein levels of CBS, MPST, and CSE are elevated with the elevation of malignant degrees in tissues and cells of human urothelial cell carcinoma of the bladder [25]. Concurrent with prior findings, our study displayed that the positive rate of CBS expression was dramatically higher in invasive $\mathrm{BC}$ tissues than in paraneoplastic tissues and lobular hyperplasia tissues. The expression of CBS was notably correlated with severe clinical situations, such as large tumor size, tumor cell invasion, LNM, and TNM stage III/IV. Furthermore, the survival rate of 


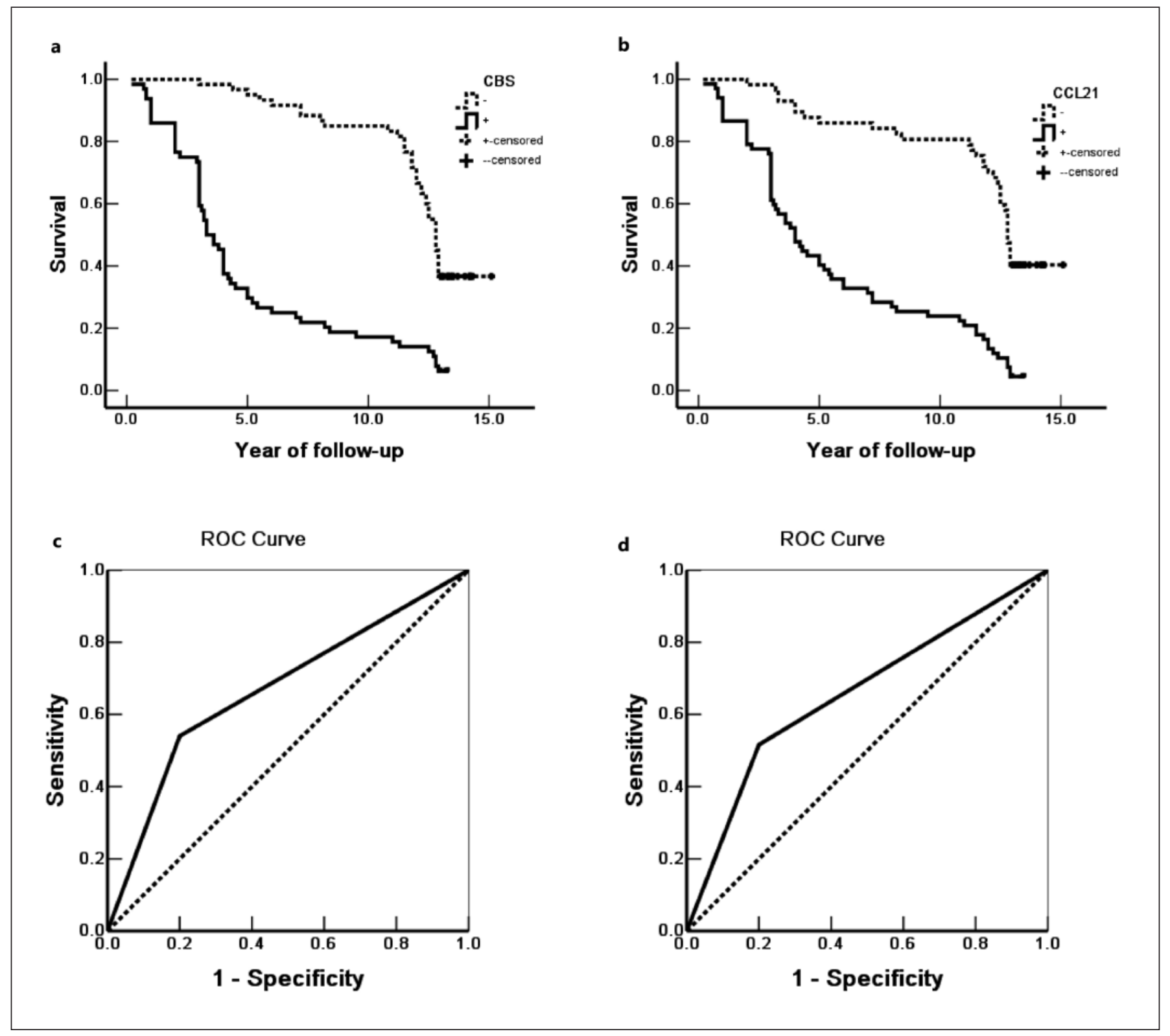

Fig. 2. Correlation between expression of CBS or CCL21 and the overall survival rate of patients with invasive BC. a Kaplan-Meier plots of the overall survival of patients with CBS-positive and with CBS-negative tumors. b Kaplan-Meier plots of the overall survival of patients with CCL21-positive and with CCL21-negative tumors. c, d The ROC curves of CBS (c) and CCL21 (d) in invasive BC. BC, breast cancer.
Fig. 3. Overexpression of CBS or CCL21 accelerates the proliferation and migration of BC cells. $\mathbf{a}, \mathbf{b}$ qRT-PCR (a) and western blot (b) were used to detect the expression of CBS and CCL21 in human BC cell lines MDA-MB-231 and MCF-7 as well as in a human normal breast epithelial cell line MCF-10A. c, d After cell transfection, the mRNA and protein levels of CBS and CCL21 in human BC cell lines were measured by qRT-PCR (c) and Western blot (d). e, f The proliferation of BC cells was evaluated by MTT assay (e) and EdU staining $(\mathbf{f}, \times 200)$. $\mathbf{g}, \mathbf{h}$ The migration of BC cells were assessed by scratch test $(\mathbf{g}, \times 100)$ and Transwell assay $(\mathbf{h}, \times 100) ;{ }^{*} p<0.05$; ${ }^{\& \&} p<0.01$, versus the MCF-10A group; ${ }^{*} p<0.05 ;{ }^{* *} p<0.01$, $* * * p<0.001$, versus the pcDNA3.1 group. BC, breast cancer; qRTPCR, quantitative real-time polymerase chain reaction.

(For figure see next page.) 

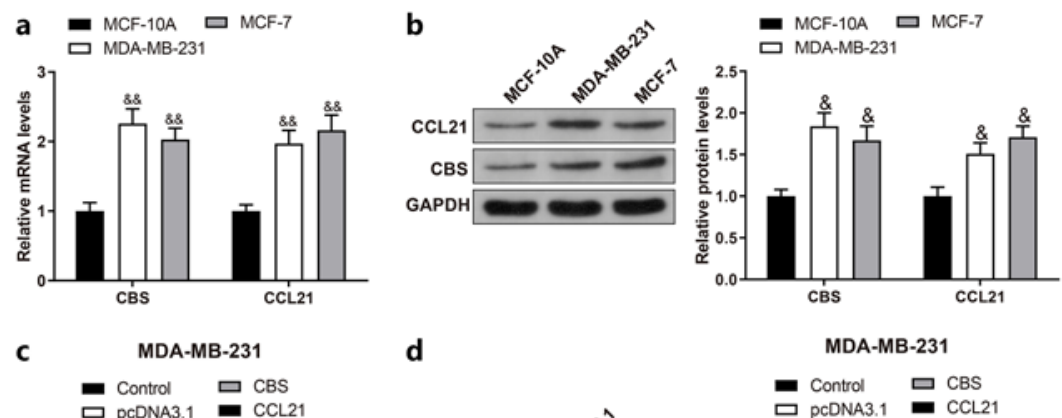

d
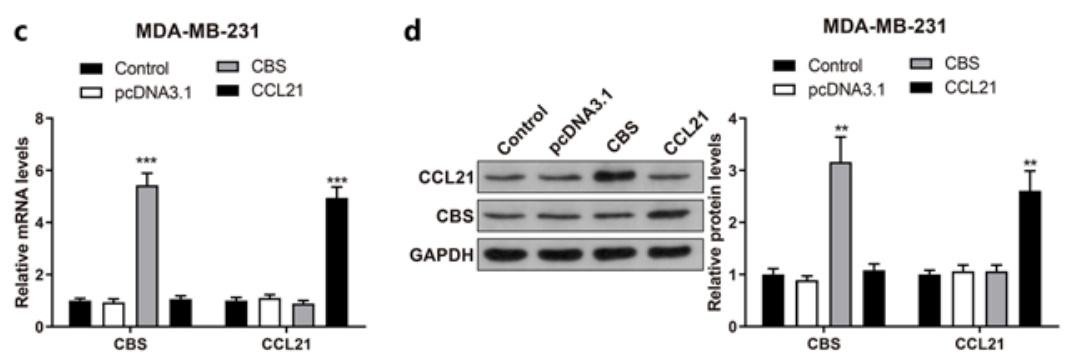

e

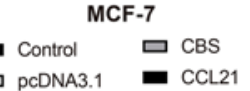

MCF-7

$\square$ pCDNA3.1 $=$ CCL2

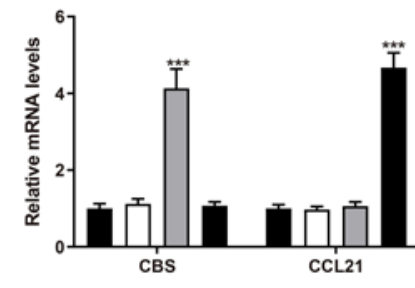

- Control $\square$ CBS

口 pCDNA3.1
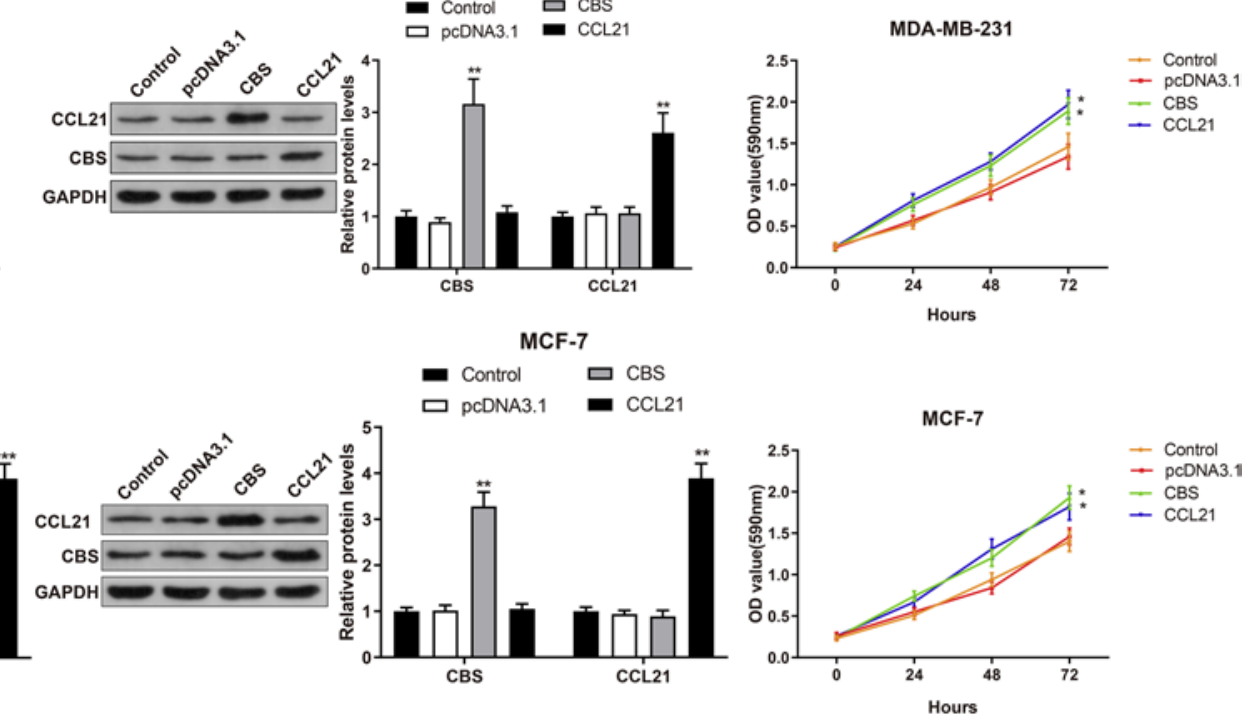

f
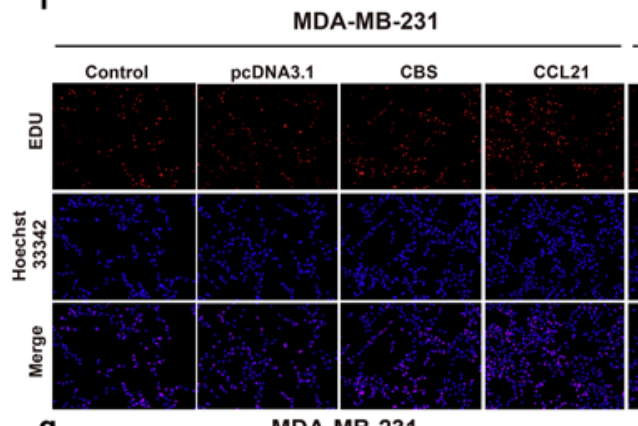

$$
\text { MCF-7 }
$$
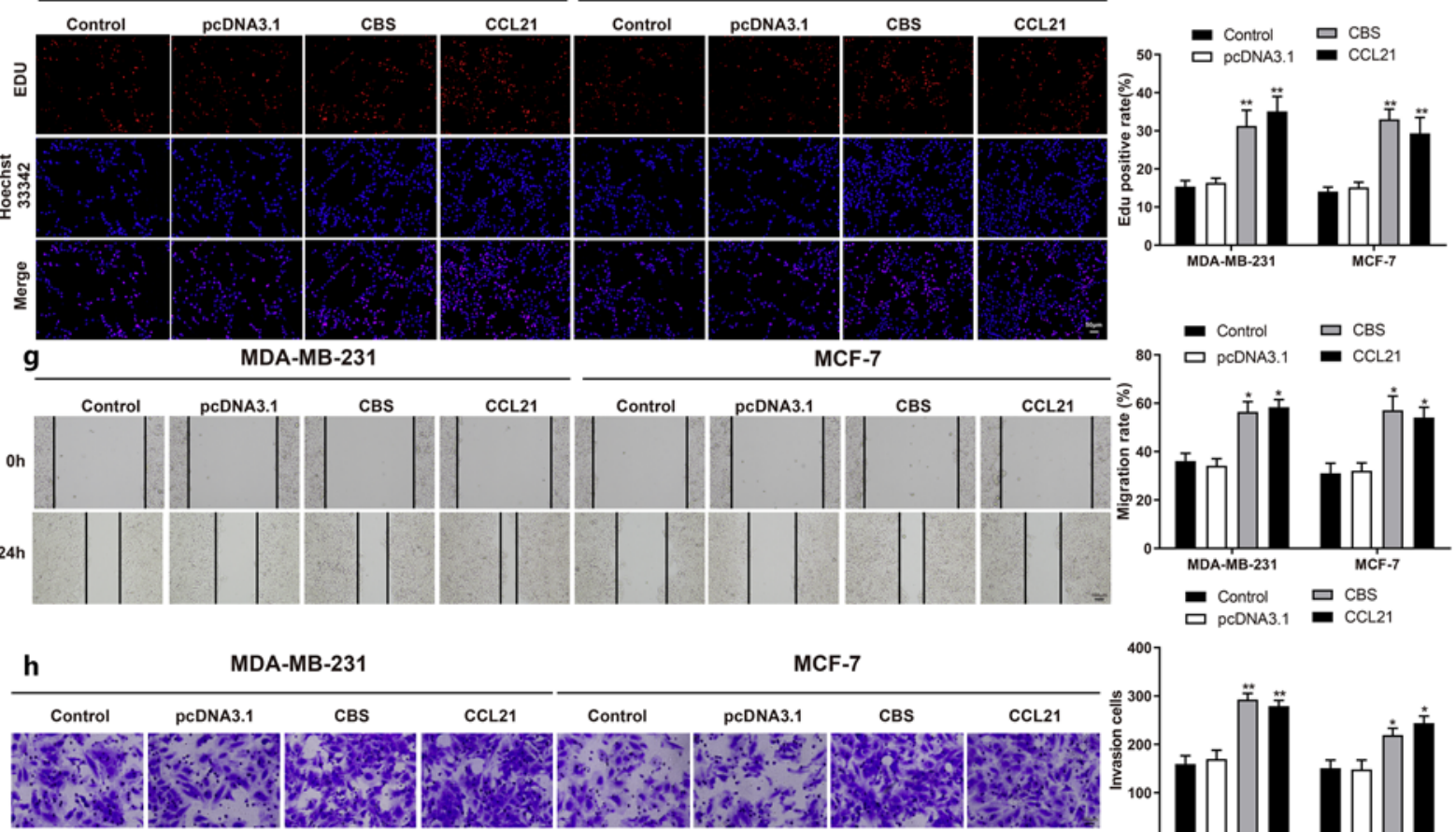

3

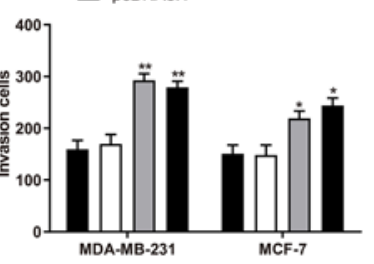




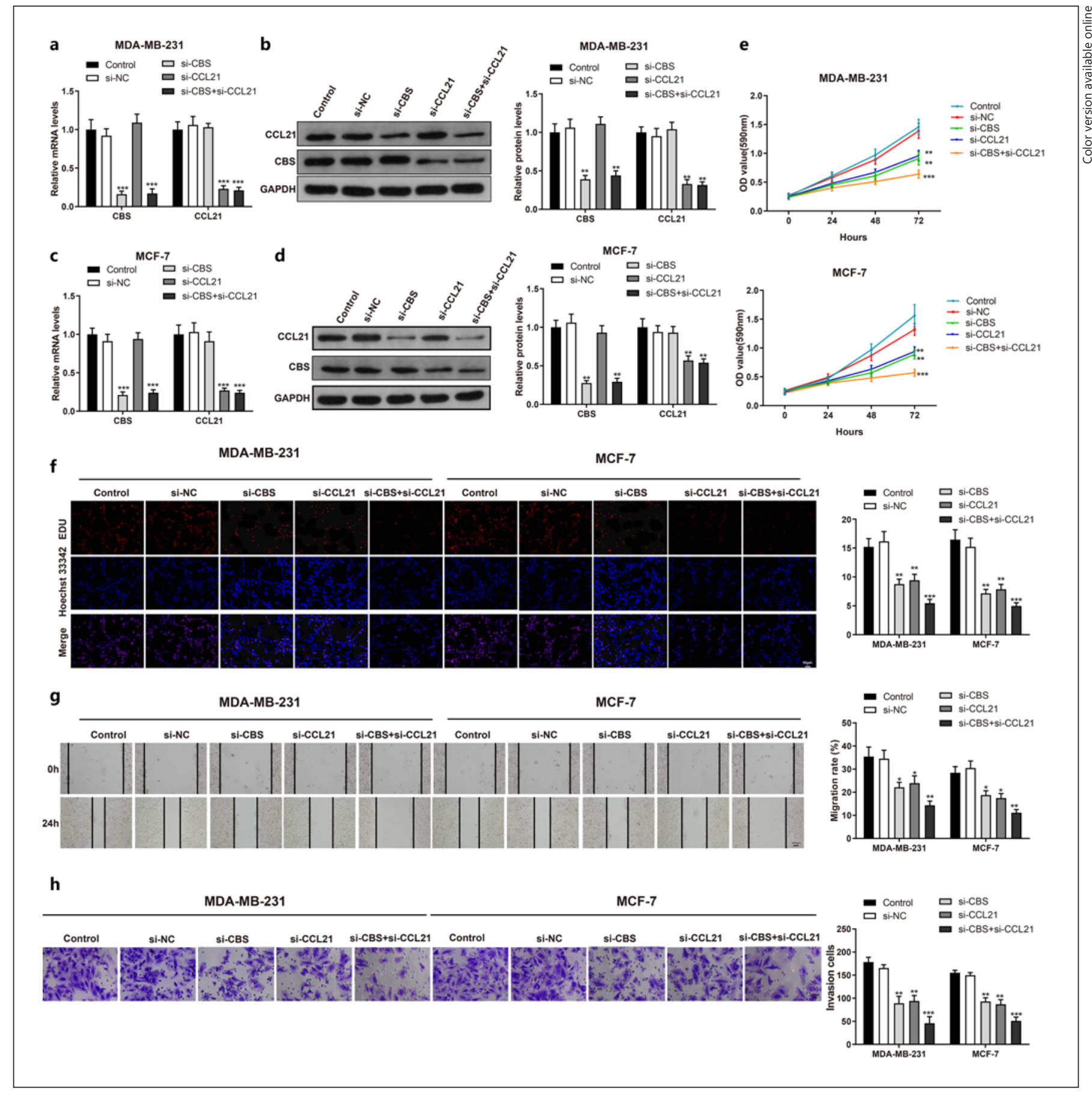

Fig. 4. Knockdown of CCL21 or CBS represses BC cell proliferation and migration. a-d After MDA-MB-231 and MCF-7 cells were transfected with si-CBS and/or si-CCL21, qRT-PCR was used to detect the mRNA expression of CBS and CCL21 in MDAMB-231 (a) and MCF-7 cells (c) and western blot to test the protein expression of CBS and CCL21 in MDA-MB-231 (b) and MCF-7 cells (d). e, $\mathbf{f}$ The proliferation ability of MDA-MB-231 and MCF-
7 cells was evaluated by MTT assay (e) and EdU staining $(\mathbf{f}, \times 200)$. $\mathbf{g}, \mathbf{h}$ Scratch test $(\mathbf{g}, \times 100)$ and Transwell assay $(\mathbf{h}, \times 100)$ were employed to detect the migration ability of $\mathrm{BC}$ cell lines; ${ }^{*} p<0.05$; ${ }^{* *} p<0.01,{ }^{* * *} p<0.001$, versus the si-NC group; ${ }^{* *} p<0.01,{ }^{* * *} p<$ 0.001 , versus the si-CBS or si-CCL21 group. BC, breast cancer; qRT-PCR, quantitative real-time polymerase chain reaction. 
patients overexpressing CBS was remarkably lower than that of patients with decreased CBS expression. The multivariate Cox regression analysis elaborated upregulated CBS as an independent poor prognostic factor for BC patients. Prior researches have documented the clinical correlations of CCL21 and CCR7 with LNM in malignant solid tumors [26, 27]. The CCL21/CCR7 chemokine axis is proven to facilitate $\mathrm{BC}$-induced lymphangiogenesis [28]. Our findings proposed that CCL21 and CBS expression was closely related to the poor prognosis of $\mathrm{BC}$ patients. Hence, the dysregulated CCL21 and CBS were speculated to control BC progression. To this end, MTT assay, EdU staining, scratch test, and Transwell assay were implemented to evaluate the impacts of CCL21 and CBS on the migratory and proliferative properties of BC cells. Subsequently, we found that the overexpression of CCL21 or CBS conferred a promotive effect on BC cell migration and proliferation after loss- and gain-of-function assays for CCL21 or CBS. Previously, CCL21 is validated to induce the deterioration of $\mathrm{BC}$ due to its ability to bind to the cognate chemokine receptors, thus promoting cell migration and proliferation [29]. Also, silencing of CBS can diminish the proliferation and metastasis potential of non-small cell lung cancer cells [30]. In light of these data, we confirmed that CBS and CCL21 might be promising therapeutic targets for $\mathrm{BC}$.

In conclusion, CBS and CCL 21 orchestrated BC progression, and CCL21 and CBS expression was related to the poor prognosis of patients with invasive BC. Furthermore, CBS and CCL21 might manipulate the biological behaviors of $\mathrm{BC}$ cells. These data potentiate the use of CBS and CCL21 as diagnostic markers and therapeutic molecules for BC. Nonetheless, these results must be interpreted with caution, and further studies are warranted to validate the results of the current study.

\section{Acknowledgments}

We thank all the contributors.

\section{Statement of Ethics}

This study was carried out according to the Declaration of Helsinki. The study protocol concerning human was approved by the Ethics Committee of the Second Xiangya Hospital of Central South University (No. 2020613), and written informed consent was obtained from all subjects.

\section{Conflict of Interest Statement}

The authors have no conflicts of interest to declare.

\section{Funding Sources}

This research received no funding.

\section{Author Contributions}

P.J. and Z.D.H. conceived the ideas. P.J. and Z.D.H. designed the experiments. P.J. performed the experiments. Z.D.H. analyzed the data. P.J. and Z.D.H. provided critical materials. P.J. wrote the manuscript. Z.D.H. supervised the study. All the authors have read and approved the final version for publication.

\section{Data Availability Statement}

The datasets used or analyzed during the current study are available from the corresponding author on reasonable request.

\section{References}

1 Harbeck N, Gnant M. Breast cancer. Lancet. 2017 Mar 18;389(10074):1134-50.

2 Siegel RL, Miller KD, Jemal A. Cancer statistics, 2017. CA Cancer J Clin. 2017 Jan;67(1): 7-30.

3 Makki J. Diversity of breast carcinoma: histological subtypes and clinical relevance. Clin Med Insights Pathol. 2015;8:23-31.

4 Wang S, Li H, Wang J, Wang D. Expression of microRNA-497 and its prognostic significance in human breast cancer. Diagn Pathol. 2013 Oct $21 ; 8: 172$.

5 Akram M, Iqbal M, Daniyal M, Khan AU. Awareness and current knowledge of breast cancer. Biol Res. 2017 Oct 2;50(1):33.
6 Anastasiadi Z, Lianos GD, Ignatiadou E, Harissis $\mathrm{HV}$, Mitsis $\mathrm{M}$. Breast cancer in young women: an overview. Updates Surg. 2017 Sep; 69(3):313-7.

7 Nola S, Sin S, Bonin F, Lidereau R, Driouch K. A methodological approach to unravel organspecific breast cancer metastasis. J Mammary Gland Biol Neoplasia. 2012 Jun;17(2):135-45.

8 Ang L, Zheng L, Wang J, Huang J, Hu HG Zou Q, et al. Expression of and correlation between BCL6 and ZEB family members in patients with breast cancer. Exp Ther Med. 2017 Nov;14(5):3985-92.
9 Wang HK, Liang JF, Zheng HX, Xiao H. Expression and prognostic significance of ECT2 in invasive breast cancer. J Clin Pathol. 2018 May;71(5):442-5.

10 Guo H, Gai JW, Wang Y, Jin HF, Du JB, Jin J. Characterization of hydrogen sulfide and its synthases, cystathionine $\beta$-synthase and cystathionine $\gamma$-lyase, in human prostatic tissue and cells. Urology. 2012 Feb;79(2):483-5.

11 Zuhra K, Augsburger F, Majtan T, Szabo C. Cystathionine-beta-synthase: molecular regulation and pharmacological inhibition. Biomolecules. 2020 Apr 30;10(5):697. 
12 Sen S, Kawahara B, Gupta D, Tsai R, Khachatryan M, Roy-Chowdhuri S, et al. Role of cystathionine beta-synthase in human breast cancer. Free Radic Biol Med. 2015 Sep;86: 228-38.

13 Szabo C, Coletta C, Chao C, Modis K, Szczesny B, Papapetropoulos A, et al. Tumorderived hydrogen sulfide, produced by cystathionine-beta-synthase, stimulates bioenergetics, cell proliferation, and angiogenesis in colon cancer. Proc Natl Acad Sci U S A. 2013 Jul 23;110(30):12474-9.

14 Chao C, Zatarain JR, Ding Y, Coletta C, Mrazek AA, Druzhyna N, et al. Cystathionine-beta-synthase inhibition for colon cancer: enhancement of the efficacy of aminooxyacetic acid via the prodrug approach. Mol Med. 2016 Sep;22:361-79.

15 Yoshida R, Nagira M, Kitaura M, Imagawa N, Imai $\mathrm{T}$, Yoshie O. Secondary lymphoid-tissue chemokine is a functional ligand for the CC chemokine receptor CCR7. J Biol Chem. 1998 Mar 20;273(12):7118-22.

16 Hirao M, Onai N, Hiroishi K, Watkins SC, Matsushima K, Robbins PD, et al. CC chemokine receptor-7 on dendritic cells is induced after interaction with apoptotic tumor cells: critical role in migration from the tumor site to draining lymph nodes. Cancer Res. 2000 Apr 15;60(8):2209-17.

17 Zlotnik A, Yoshie O. Chemokines: a new classification system and their role in immunity. Immunity. $2000 \mathrm{Feb}$;2(2):121-7.
18 Cassier PA, Treilleux I, Bachelot T, Ray-Coquard I, Bendriss-Vermare N, MenetrierCaux C, et al. Prognostic value of the expression of C-chemokine receptor 6 and 7 and their ligands in non-metastatic breast cancer. BMC Cancer. 2011 May 30;11:213.

19 Sancho M, Vieira JM, Casalou C, Mesquita M, Pereira T, Cavaco BM, et al. Expression and function of the chemokine receptor CCR7 in thyroid carcinomas. J Endocrinol. 2006 Oct; 191(1):229-38.

20 Shi M, Chen D, Yang D, Liu XY. CCL21CCR7 promotes the lymph node metastasis of esophageal squamous cell carcinoma by upregulating MUC1. J Exp Clin Cancer Res. 2015 Dec 15;34:149.

21 Xia X, Liu K, Zhang H, Shang Z. Correlation between CCR7 expression and lymph node metastatic potential of human tongue carcinoma. Oral Dis. 2015 Jan;21(1):123-31.

22 Zou Y, Chen Y, Wu X, Yuan R, Cai Z, He X, et al. CCL21 as an independent favorable prognostic factor for stage III/IV colorectal cancer. Oncol Rep. 2013 Aug;30(2):659-66.

23 Kajimura M, Fukuda R, Bateman RM, Yamamoto T, Suematsu M. Interactions of multiple gas-transducing systems: hallmarks and uncertainties of $\mathrm{CO}, \mathrm{NO}$, and $\mathrm{H} 2 \mathrm{~S}$ gas biology. Antioxid Redox Signal. 2010 Jul 15;13(2): 157-92.

24 Bhattacharyya S, Saha S, Giri K, Lanza IR, Nair KS, Jennings NB, et al. Cystathionine beta-synthase (CBS) contributes to advanced ovarian cancer progression and drug resistance. PLoS One. 2013;8(11):e79167.

25 Gai JW, Qin W, Liu M, Wang HF, Zhang M, Li M, et al. Expression profile of hydrogen sulfide and its synthases correlates with tumor stage and grade in urothelial cell carcinoma of bladder. Urol Oncol. 2016 Apr;34(4):166. e15-20.

26 Xu Y, Liu L, Qiu X, Jiang L, Huang B, Li H, et al. CCL21/CCR7 promotes G2/M phase progression via the ERK pathway in human nonsmall cell lung cancer cells. PLoS One. 2011; 6(6):e21119.

27 Xiong Y, Huang F, Li X, Chen Z, Feng D, Jiang $\mathrm{H}$, et al. CCL21/CCR7 interaction promotes cellular migration and invasion via modulation of the MEK/ERK1/2 signaling pathway and correlates with lymphatic metastatic spread and poor prognosis in urinary bladder cancer. Int J Oncol. 2017 Jul;51(1): 75-90.

28 Tutunea-Fatan E, Majumder M, Xin X, Lala PK. The role of CCL21/CCR7 chemokine axis in breast cancer-induced lymphangiogenesis. Mol Cancer. 2015 Feb 10;14:35.

29 Rizeq B, Malki MI. The role of CCL21/CCR7 chemokine axis in breast cancer progression. Cancers. 2020 Apr 23;12(4):1036.

$30 \mathrm{Xu} \mathrm{H}$, Jia Z, Ma K, Zhang J, Dai C, Yao Z, et al. Protective effect of BMSCs-derived exosomes mediated by BDNF on TBI via miR216a-5p. Med Sci Monit. 2020 Mar 9;26: e920855. 